\title{
Study of Modeling and Simulation of Methanol Engine Electronic Control
}

\author{
System \\ WuXiaozhen, HeMiao \\ Nanchang Institute of Science \&Technology,Nanchang 330108,China
}

\begin{abstract}
Key words: alcohol hydrogen power; MAP grid; interpolation algorithm; electronic control system; Simulink simulation
\end{abstract}

\begin{abstract}
In order to improve the control effect of alcohol and hydrogen power system and accomplish control target of dissociated methanol engine, a electronic control model based on the MAP grid interpolation method has been put forward, and the software of Simulink has been used to simulate and verify the model. According to the establishment of the control strategy and algorithm, the ECU function is calculated, the MAP grid computing results after using interpolation have been obtained, and finally the experimental values and simulation values are compared. The results show that it has a high precision using Simulink simulation model. The comparison error of simulation and experimental results is less than 5\%, the more accurate MAP electronic control three-dimensional map can be got, continuity and smoothness of the image is better, electronic control injection quantity at arbitrary rotation speed and the throttle opening degree can be checked.
\end{abstract}

\section{Introduction}

The 21st century is the era of the rapid development of oil and computer, especially the development and dependence degree of oil reached the unprecedented degree. With the prosperity of the automotive market, demand for oil is increasing, but at the same time oil reserves also have sharply reduced, which makes people facing unprecedented energy and environmental challenges. At present, saving energy and protecting the environment is the theme of the times, the technological revolution as the core of new energy technology has been set off all over the world, including the use of new energy vehicles and electric vehicles. And taking methanol cracking gas as automobile power materials not only can solve the problem of lack of oil reserves, and its combustion products less polluted air, because the dissociated methanol is hydrogen and carbon monoxide. Therefore, it has become hot spot in study of new energy automobiles.

\section{Methanol dynamic system characteristics and cracking model}

If the methanol liquid is directly used as the engine fuel, its thermodynamic performance is poor, and if the methanol is cracked into gas, the thermodynamic performance will be greatly improved. Such as cracking methanol to hydrogen and carbon monoxide, which can save $14 \%$ of fuel and low calorific value of dissociated methanol increased by $20 \%$ compared with the single use of methanol, at the same time the thermal efficiency is greatly improved. the data comparison has been given in Tab. 1, including separate use liquid methanol, methanol steam, and the use of dissociated methanol and gasoline. 
Table 1 Comparison of low calorific value of different fuel components

\begin{tabular}{|l|c|}
\hline \multicolumn{1}{|c|}{ Fuel type } & Calorific value (KJ/Kg) \\
\hline Methanol liquid & 19.98 \\
\hline Methanol steam & 22 \\
\hline $\begin{array}{l}\text { Dissociated methanol (hydrogen } \\
\text { and carbon monoxide) }\end{array}$ & 23.85 \\
\hline Gasoline & 43.92 \\
\hline Methanol gasoline & 22.1 \\
\hline
\end{tabular}

It can be seen From data in Table 1 that, although when using methanol steam and dissociated methanol, the calorific value is not high as using gasoline, but when using methanol steam, the calorific value is obvious high compared with using methanol liquid, and the calorific value of using dissociated methanol is significantly more high than using methanol steam, so it can better improve the thermodynamic performance of fuel when taking dissociated methanol as engine fuel.

Tab.2 The increase of low calorific value in methanol cracking process

\begin{tabular}{|c|l|c|}
\hline \multicolumn{2}{|c|}{ Reaction equation } & Increase percentage of low calorific value (\%) \\
\hline \multirow{3}{*}{$\begin{array}{c}\text { Cracking } \\
\text { reaction }\end{array}$} & $\mathrm{CH}_{3} \mathrm{OH}(\mathrm{L})+\mathrm{Q}=\mathrm{CH}_{3} \mathrm{OH}(\mathrm{V})$ & 7 \\
\cline { 2 - 3 } & $\mathrm{CH}_{3} \mathrm{OH}(\mathrm{V})+\mathrm{Q}=\mathrm{H}_{2}+\mathrm{CO}$ & 21 \\
\cline { 2 - 3 } & $\mathrm{CH}_{3} \mathrm{OH}(\mathrm{L})+\mathrm{Q}=\mathrm{H}_{2}+\mathrm{CO}$ & 8 \\
\hline \multirow{2}{*}{$\begin{array}{c}\text { Integrated } \\
\text { reaction }\end{array}$} & $\mathrm{CH}_{3} \mathrm{OH}(\mathrm{V})+\mathrm{H}_{2} \mathrm{O}+\mathrm{Q}=\mathrm{H}_{2}+\mathrm{CO}$ & 16 \\
\cline { 2 - 3 } & $\mathrm{CH}_{3} \mathrm{OH}(\mathrm{L})+\mathrm{H}_{2} \mathrm{O}+\mathrm{Q}=\mathrm{H}_{2}+\mathrm{CO}$ & 21 \\
\hline
\end{tabular}

Methanol cracking is a very complicated process, the pyrolysis process need to join the appropriate catalyst, and the heat absorption process needs to absorb heat, the material forms will also change greatly. This study focuses on the smooth operation of the engine electronic control system. The cracking reaction is only used as the calculation model, the structure model of methanol cracking is shown in Figure 1.

Figure 1 shows the model schematic diagram of methanol cracking process and engine control system. Firstly, methanol liquid is heated by the engine exhaust gas temperature, then methanol is fed into the evaporator for evaporation, methanol gas after evaporation is fed into reactor to carry out cracking reaction, the obtained gas is fed into engine channel, then mixing it with the air in a cylinder of the engine combustion, producing heat, which can promote the normal operation of the engine system. 


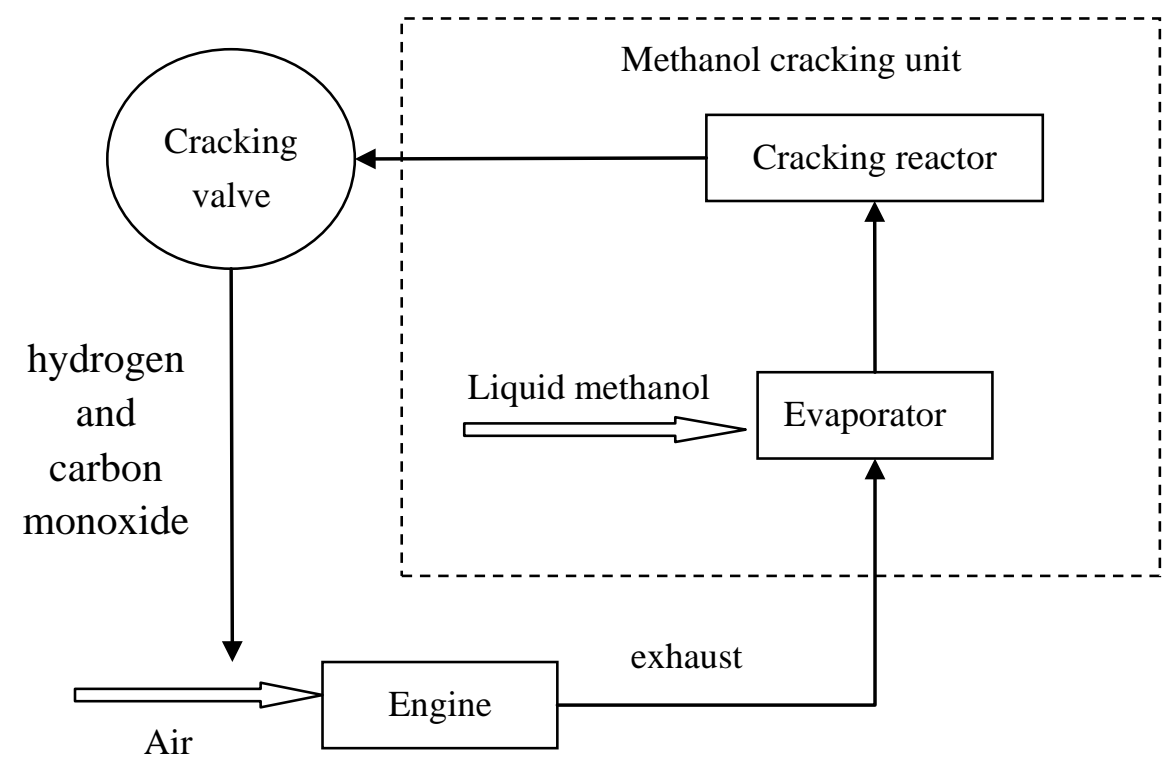

Fig. 1 Structure model of methanol cracking reactor

\section{Strategy and algorithm of methanol engine electronic control power system}

The method of three dimensional interpolation can be used in the control model of the methanol power electronic control system, and the control system is calculated and simulated by the data processing of the MAP electric control model. Suppose that one dimension parameter in the model is the engine speed $n$, and the other dimension parameter is the throttle opening $\alpha$, the MAP electronic control grid is shown in Figure 2.

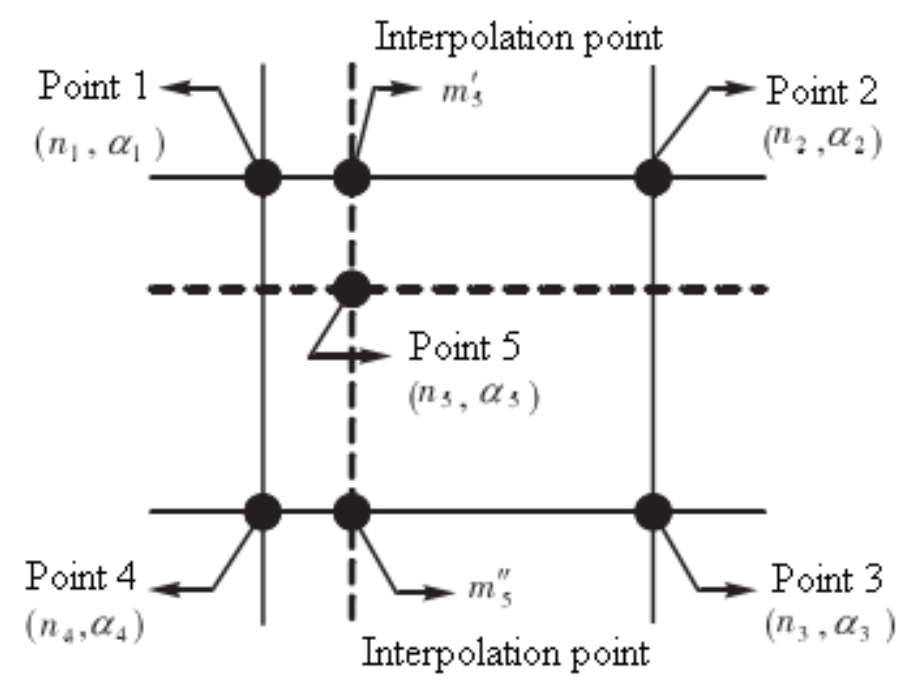

Fig.2 MAP electronic control grid

Figure 2 shows the MAP electronic control grid, points 1-4 in the grid is 2D data points of experimental MAP grid, each point can control engine speed $n$ and throttle opening $\alpha$ in the way of single point control, getting the reasonable injection quantity $m$. Point 5 is the operating point in the actual working process of the methanol engine, which is not coincident with the points in the MAP grid, so it needs to be solved by interpolation. First we should determine the location of the operating Point 5, and then determine the 4 fixed points near the engine speed $n$ and the throttle opening $\alpha$, the value of $m_{5}{ }^{\prime}$ can be got after interpolation, the expression is Formula (1). 


$$
m_{5}^{\prime}=\frac{m_{2}\left(\alpha_{5}-\alpha_{1}\right)+m_{1}\left(\alpha_{2}-\alpha_{5}\right)}{\alpha_{2}-\alpha_{1}}
$$

After interpolation, interpolating according to the throttle opening $\alpha_{3}, \alpha_{4}$, getting $m_{5}{ }^{\prime \prime}$, the calculation formula is Formula (2).

$$
m_{5}^{\prime \prime}=\frac{m_{3}\left(\alpha_{5}-\alpha_{4}\right)+m_{4}\left(\alpha_{3}-\alpha_{5}\right)}{\alpha_{3}-\alpha_{4}}
$$

For the final solution of Point 5, interpolation is needed in the direction of $\alpha_{3}, \alpha_{4}$, and the interpolation formula is Formula (3).

$$
m_{5}=\frac{m_{5}^{\prime}\left(n_{4}-n_{5}\right)+m_{5}^{\prime \prime}\left(n_{5}-n_{1}\right)}{n_{4}-n_{1}}
$$

The MAP electronic control grid can also be used to specify the gradient $\partial m / \partial n$ and $\partial m / \partial \alpha$, and the mixed derivative $\partial^{2} m /(\partial n \partial \alpha)$, according to the gradient, the 5 points of the methanol fuel control $m_{5}\left(n_{5}, \alpha_{5}\right)$ can be easily calculated. The method of interpolation can be used in solution of 5 points, which can achieve the continuity from a grid change to another, so that the obtained map control data can be more smooth, and the establishment of the model can use SIMULINK simulation modeling tools in MATLAB software.

\section{Modeling and Simulation of methanol power system based on Simulink}

This study using the Simulink module of MATLAB software to establish dynamic model of methanol engine, and the ECU module has been added on base of the engine mathematical model, and then methanol power model will have function of electronic control system. Through numerical simulation and simulation calculation, we get the MAP electronic control results as shown in Fig.3.

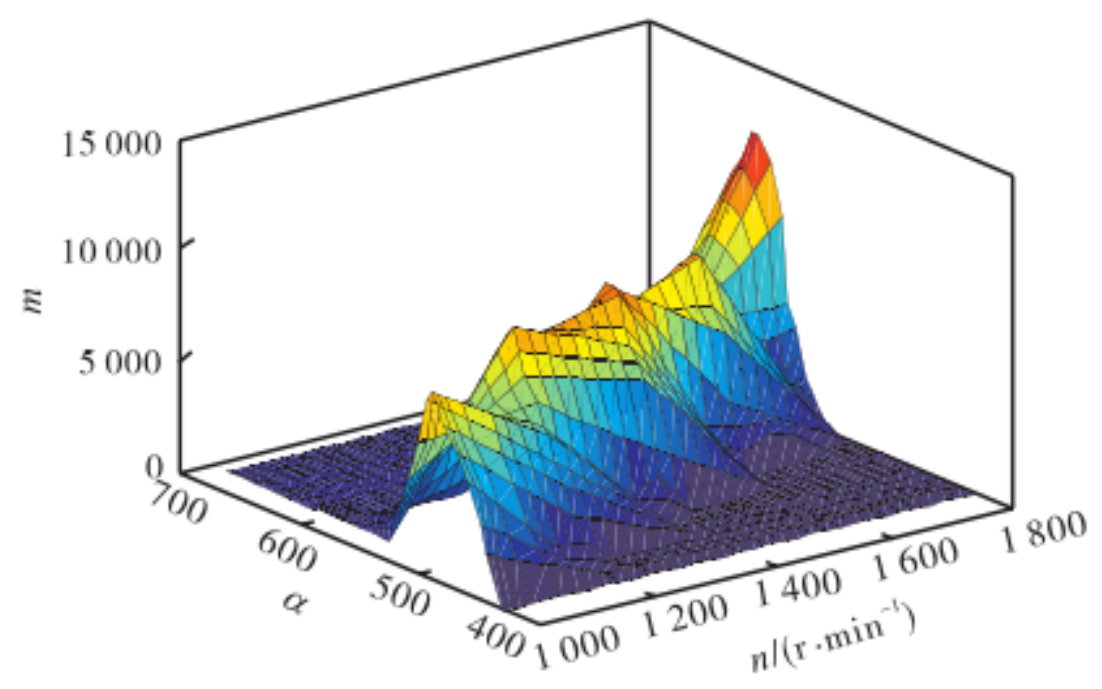

Fig. 3 Electronic control MAP diagram of methanol engine

Figure 3 shows electronic MAP simulation calculation 3D effect graph of the methanol engine. From the results, it can be seen that continuity and smoothness of the electronic control MAP graph is better by interpolation method. In the process of engine running, the methanol control amount correspond to any speed and throttle open also can be got, which can be seen in Fig.3. 


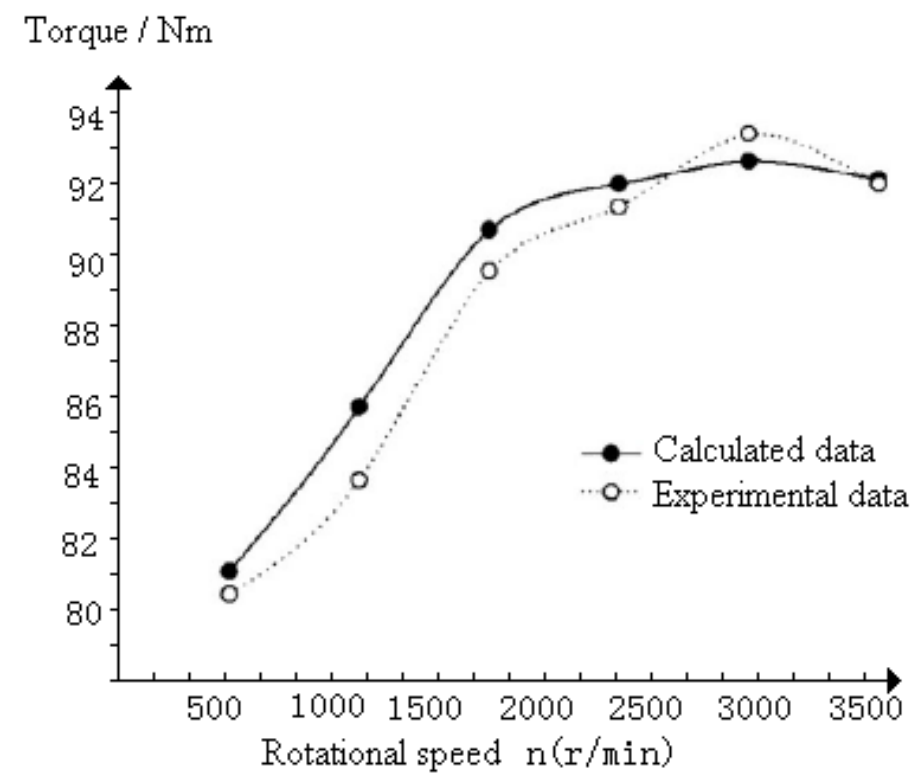

Fig. 4 Comparison curves of experimental and simulation calculation

Figure 4 shows simulation and experimental comparison of data curve, it can be seen that the data obtained by the two basically tallies, error is less than $5 \%$ from the chart. Thus it can be known taht simulation model established Simulink has higher accuracy, which can meet the needs of model design and the 3D graph of more accurate MAP electronic control can be got.

\section{Conclusion}

This study proposed a new electronic control model in method of MAP grid interpolation, and the electric control model was simulated in the method of Matlab-Simulink modeling, and the ECU control modeling, the error comparison curves and MAP grid simulation calculation diagram has been got by calculating. The experimental and numerical calculation results show that experiments and numerical calculation data are basically consistent, the error is less than $5 \%$, and more accurate 3D MAP electronic control grid can be got by the use of numerical interpolation calculation method, the methanol control amount correspond to any speed and throttle open also can be got.

\section{Acknowledgement}

The work was supported by the the key subject of science and technology project of Jiangxi Education Department with the project number GJJ151235 and the project name Research and Realization of Electric Control System in Alcohol Hydrogen Power System Device Based on PLC.

\section{Reference}

[1] Xu Yuanli, Yao Chunde. Li Xucong. The design of the cracking device and its experiments on the electronic controlled engine [J]. Journal of Tianjin University. 2012,54 (3): 274-276.

[2] Yao Chunde, Wang Yinshan, Li Yunqiang, et al. The electronic control system of intake air pre mixed methanol diesel engine [J]. Journal of Tianjin University, 2005, 38 (2):133-136.

[3] Li Yi, high Guangxin, Liu Shenghua, ambient temperature of methanol, gasoline engine cold start emissions that affect the study[J]. Journal of Xi'an Jiaotong University.2011,54 (11): 7-9. 
[4] Gong Changming, Zhang Zilei, Jia Jinglong, Cui Fengyun. Ignition cylinder straight injection methanol engine formaldehyde and bud methanol emission characteristics[J]. Journal of Jilin University. 2012,24 (4) 868-870.

[5] Yao Dongwei, Wu Feng, Ling Xingchen. Modeling and Simulation of dynamic characteristics of gasoline engine intake [J]. Chinese Internal Combustion Engine Engineering, 2012.6 (33): 60-61

[6] Zhao Yanan, Zhao Futang, Jing Su Tong. Research on excitation signal model of electronic control unit for engine [J]. Transactions of Beijing Institute of Technology, 2007,27 (6) is: 506-509.

[7] Zheng Qingping, Sun Hailiang, Li Su. Optimization of the phase of the ignition of methanol engine[J]. Journal of Hebei University of Technology.2012,39 (4): 79-82.

[8] Zhang Zhongrong, Fan Guoliang, Hou Yanfeng. Spark ignition electronically controlled methanol engine unconventional pollutants emission characteristics[J]. Journal of Combustion science and Technology, 2006,12 (1): 86-89.

[9] Chen Weifang. The effect of M15 methanol gasoline on engine emission [J].Chinese Internal Combustion Engine Engineering.2009,30 (3): 28-30.

[10] Yao Chunde, Huang Yu, Li Shuai, et al. Experimental study on the effect of different substitution ratio of methanol on DMCC emission [J]. Transactions of Csice, 2008, 26 (2):134-139.

[11] Wei Yanju. Study on the characteristics and influence factors of methanol aldehyde emission in methanol gasoline engine [J]. Journal of Xi'an Jiao Tong University,.2011,1 (54): 1-3.

[10] Wei Chunnuan. Design of greenhouse monitoring and control system based on Zigbee technology [J]. Electronic Component \& Device Applications, 2011, 03 (13):17-23.

[11] Chen Yunpeng, Long Hui, Liu Zhijie. Research status and Countermeasures of fertilization technology and fertilizer application in China [J]. Journal of Agricultural Mechanization Research, 2015 (4): 255-260

[12] Ji Jiangtao, Zheng Zhihua, Du Mengmeng. Research status and development trend of agricultural robot [J]. Journal of Agricultural Mechanization Research, 2014 (12): 1-4

[13] Qiao Yongliang, He Dongjian, Zhao Chuanyuan, etc.. Based on the multi spectral images and SVM corn field weed recognition [J]. Journal of Agricultural Mechanization Research, 2013 (8): 30-34

[14] Lv Shengchun, Li Hui. Study on measurement method of non conventional emission components of methanol and gasoline mixed fuel engine[J]. Transactions of Csice.2006.24 (1): 58-60.

[15] Wang Lijun, Liu Shenghua, Zou Bo, Ma Jing. Study on combustion and emission characteristics of high proportion methanol diesel dual fuel engine[J]. Journal of Xi'an Jiao Tong University, 2007,14 (1): 15-17.

[16] Zhu Jianjun, Kou Ziming, Wang Shuping, Zheng Guozhang. Research and development of cold start system of pure methanol engine[J]. Automotive Engineering, 2011,33 (4): 209-300. 